Check for updates

Cite this: Chem. Sci., 2018, 9, 7230

๑ All publication charges for this article have been paid for by the Royal Society of Chemistry

Received 6th May 2018

Accepted 2nd August 2018

DOI: $10.1039 / \mathrm{c} 8 \mathrm{sc} 02038 \mathrm{~h}$

rsc.li/chemical-science

\section{Photocatalytic Barbier reaction - visible-light induced allylation and benzylation of aldehydes and ketones $\dagger$}

\author{
Anna Lucia Berger, Karsten Donabauer and Burkhard König (DD *
}

We report a photocatalytic version of the Barbier type reaction using readily available allyl or benzyl bromides and aromatic aldehydes or ketones as starting materials to generate allylic or benzylic alcohols. The reaction proceeds at room temperature under visible light irradiation with the organic dye 3,7-di(4biphenyl)1-naphthalene-10-phenoxazine as a photocatalyst and DIPEA as sacrificial electron donor. The proposed cross-coupling mechanism of a ketyl- and an allyl or benzyl radical is supported by spectroscopic investigations and cyclic voltammetry measurements.

\section{Introduction}

Although first reported over a century ago, Barbier-type reactions are still important tools for carbon-carbon bond formations in organic synthesis today. ${ }^{1}$ In the classical Barbier reaction a metal, e.g. zinc $^{2}$ or magnesium ${ }^{3}$ is able to insert in the carbon-halide bond of a reactive organic halide to form a nucleophilic organometallic intermediate 4 which can undergo a reaction with various electrophiles, like aldehydes or ketones to form the corresponding secondary or tertiary alcohols as products (Scheme 1a). One of the main application of Barbier reactions is the synthesis of allylic or benzylic alcohols from an aldehyde or ketone and allyl or benzyl bromide using a metal as reductant. ${ }^{4}$ Over the years, Barbier-type reactions have been developed further, and today they are known for many different substrates ${ }^{5}$ and with various metals e.g. tin, ${ }^{6}$ indium, ${ }^{7}$ praseodymium ${ }^{8}$ or manganese. ${ }^{9}$ While these methods offer a wide variety of reaction conditions, they all are overall two-electron processes which is why they require the use of a stoichiometric amount of metal as a reductant. Using a photoredox catalyst to access an organic electron source instead of a metal would represent an interesting and more environmentally benign alternative. However, photoredox catalyzed twoelectron processes are scarce, as photocatalytic reactions usually proceed via radical intermediates that are generated by a photoinduced single electron transfer (SET). ${ }^{10}$ To generate carbanion synthons with similar reactivity as the nucleophilic organometallic intermediate in classical Barbier-type reactions, two consecutive SETs would be required to generate a radical

Institut für Organische Chemie, Universität Regensburg, Universitätsstrasse 31, 93053 Regensburg, Germany. E-mail: Burkhard.Koenig@chemie.uni-regensburg.de; Fax: +49941-943-1717; Tel: +49-941-943-4575

$\dagger$ Electronic supplementary information (ESI) available. See DOI: $10.1039 / \mathrm{c} 8 \mathrm{sc} 02038 \mathrm{~h}$ first followed by another reduction to the corresponding carbanion. ${ }^{11}$ Due to the high reactivity of most radicals and their low concentration in photocatalytic reactions this process is rather unlikely. Another strategy to enable photocatalytic two-electron processes would be a reductive radical-radical cross coupling where one electron is transferred to each starting material, generating two radical intermediates that can recombine to give the desired product (Scheme 1b). ${ }^{12}$ Photocatalytic reductions of

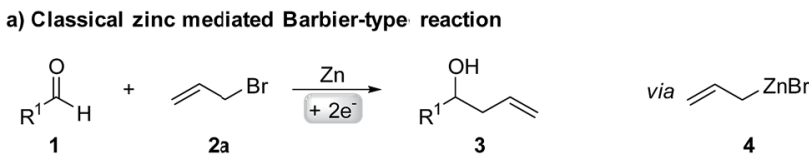

b) This work

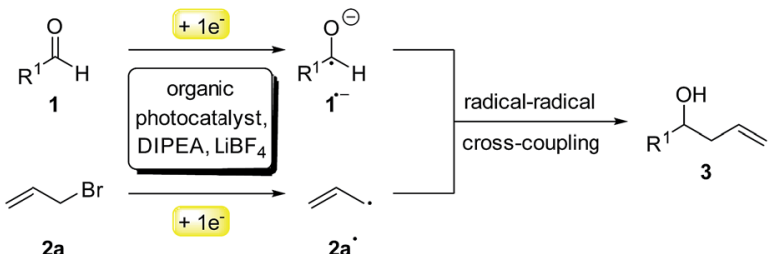

$2 a$

$2 a^{\circ}$

c) Photoredox-catalyzed reductive coupling of aldehydes and ketones

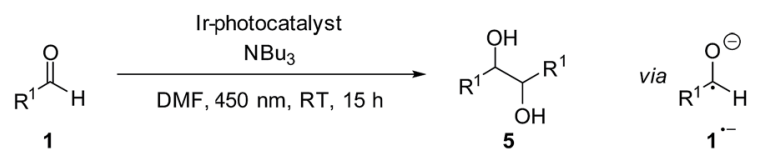

d) Polarity-reversed allylation of aldehy/des and ketones

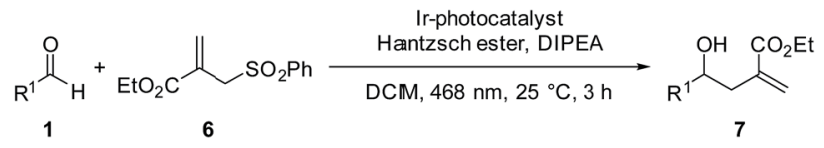

Scheme 1 (a) Classical and (b) photocatalytic version of the Barbiertype reaction; (c and d) other photocatalytic reactions with ketyl radicals. 
aromatic aldehydes to the corresponding alcohols have been known since a report by Pac et al. in 1983 (ref. 13) and in 1990 the formation of diols as homocoupling products of ketyl radical anions has been observed. ${ }^{\mathbf{1 4}}$

After having been used only rarely in photoredox catalysis for many years, there has been an increasing number of reports about photocatalytic reductions of aldehydes and ketones recently. Ketyl radicals have often been used for radical-radical coupling reactions, ${ }^{12,15}$ e.g. in the work of Rueping and coworkers about a photoredox-catalyzed reductive dimerization of aldehydes and ketones (Scheme $1 \mathrm{c})^{\mathbf{1 5 b}}$ or in the reductive arylation of carbonyl derivatives by Xia et al. in 2017. ${ }^{12}$ Apart from radical-radical coupling reactions, it is also possible to use ketyl radicals for cyclization reactions ${ }^{\mathbf{1 6}}$ or to trap them intermolecularly with alkenes. ${ }^{17}$ In the work of Chen and co-workers, hydroxymethyl radicals derived from the photocatalytic reduction of aldehydes or ketones are added to allyl sulfones (Scheme 1d) to form the corresponding homoallylic alcohols as products. ${ }^{17 a}$ While this is an elegant method for the photocatalytic allylation of aldehydes and ketones, it is only possible for allyl sulfones with electron withdrawing $\mathrm{CO}_{2}$ Et-groups. A photochemical method for the allylation and benzylation of ketones and 1,2-diketones using organotrifluoroborate has been reported in 2009 by Nishigaichi et. al. ${ }^{18}$ We developed a method for the direct photocatalytic synthesis of allylic and benzylic alcohols from ketones or aldehydes and allyl or benzyl bromides with an organic photocatalyst via a reductive radical-radical cross coupling.

\section{Results and discussion}

For the optimization of the reaction conditions, we used the readily available substrates benzaldehyde (1a) and allyl bromide (2a) as starting materials. Initial experiments have shown that we could obtain $22 \%$ of the desired product $3 a$ when the reaction was performed in dry DMF with $4 \mathrm{CzIPN}$ (A) as a photocatalyst and DIPEA as sacrificial electron donor (Table 1, entry 1).

By using 3,7-di(4-biphenyl) 1-naphthalene-10-phenoxazine (B) as a photocatalyst ${ }^{19}$ the yield could be increased to $38 \%$ (Table 1 - entry 2) and by changing the irradiation wavelength from 455 to $400 \mathrm{~nm}$ and the solvent from DMF to DMA a yield of $54 \%$ could be obtained (Table 1 - entry 3 ). With the iridiumbased photocatalyst $\mathbf{C}$ only $21 \%$ of 3 a was formed (Table 1 entry 4). By adding 1.5 equivalents of $\mathrm{LiBF}_{4}$ to the reaction mixture the formation of the diol homocoupling product of $\mathbf{1 a}$ could be suppressed, which further increased the yield to $64 \%$ (Table 1 - entry 5). ${ }^{15 a}$ Reducing the reaction time from 18 to 2 hours only slightly decreased the yield (Table 1 - entry 6).

While light and DIPEA are necessary for product formation (Table 1 - entries 7 and 8), the reaction also works in moderate

Table 1 Optimization of the reaction conditions ${ }^{a}$

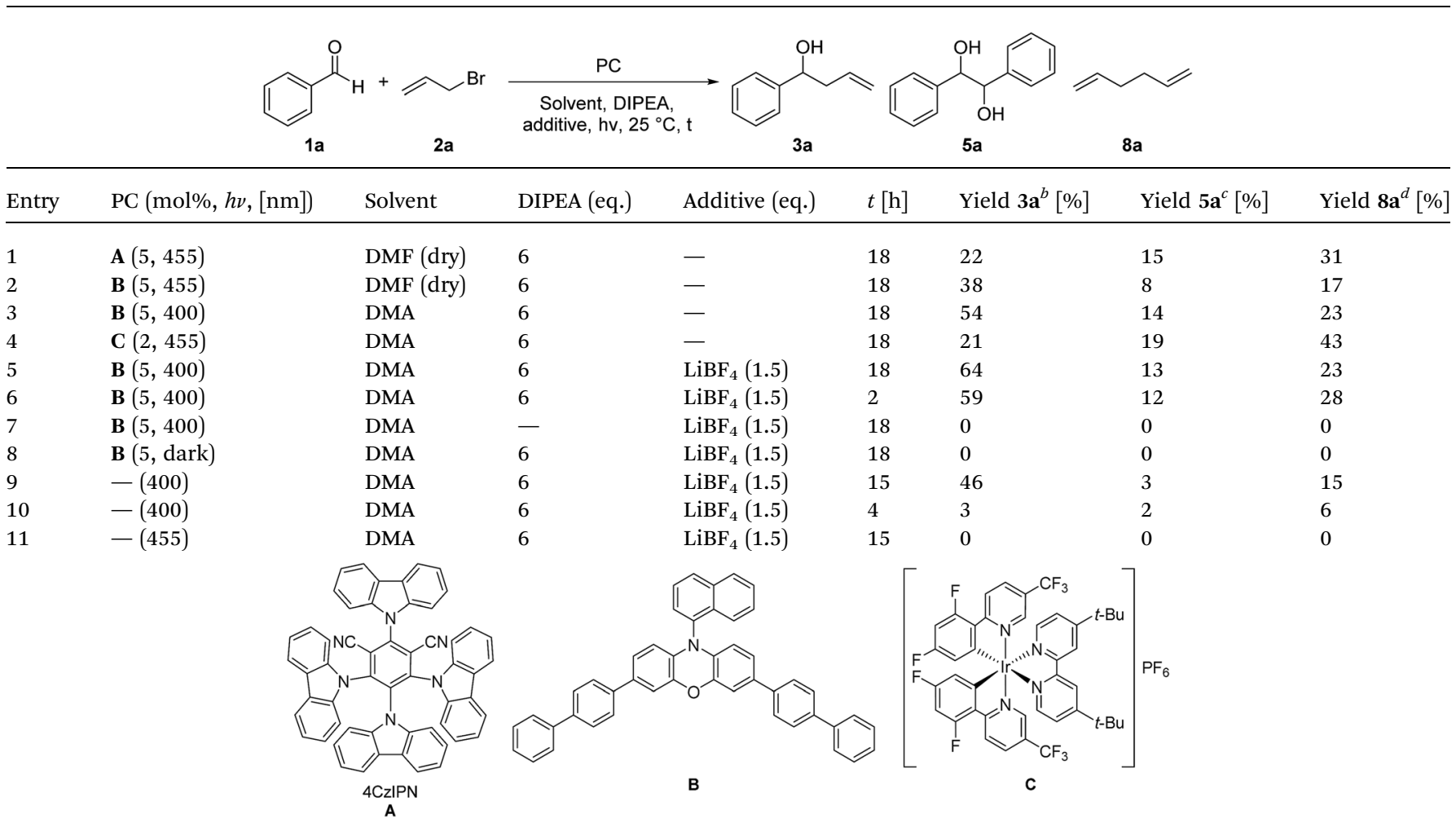

\footnotetext{
${ }^{a}$ The reactions were performed using 1 eq. $(0.2 \mathrm{mmol})$ 1a and 2 eq. $(0.4 \mathrm{mmol}) 2 \mathrm{a}$ in $2 \mathrm{~mL}$ degassed solvent under nitrogen. ${ }^{b}$ Yields were determined by GC analysis with 1-naphthol as an internal standard. ${ }^{c}$ Yields were determined by crude NMR with $1,3,5$-trimethoxybenzene as an internal standard. ${ }^{d}$ Yields were determined by GC analysis with 1-naphthol as an internal standard.
} 
yields without photocatalyst at $400 \mathrm{~nm}$ (46\%, Table 1 - entry 9). However, the presence of the photocatalyst significantly accelerates the reaction as we already obtain complete conversion after 3 hours with $5 \mathrm{~mol} \%$ of $\mathbf{B}$, while only traces of 3a were formed after the same time without photocatalyst (Table 1 entry 10). When the reaction was performed at $455 \mathrm{~nm}$ without B no product formation could be observed (Table 1 - entry 11). As shown in Table 1, varying amounts of the homocoupling products 5a and $\mathbf{8 a}$ are formed under all tested reaction conditions. Due to the use of an excess of allyl bromide (2a), the generation of $\mathbf{8 a}$ has little influence on the yield of the reaction. In contrast, the formation of the diol homocoupling product $\mathbf{5 a}$ decreases the yield of the desired product significantly, as two

Table 2 Scope of the reaction ${ }^{a}$

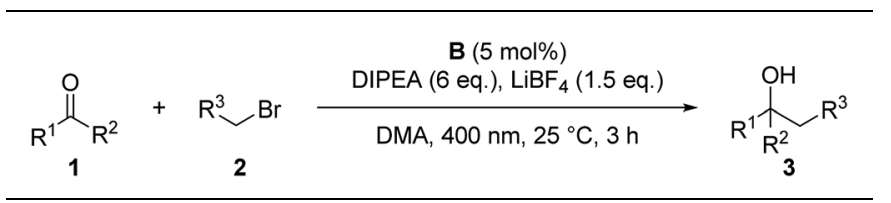

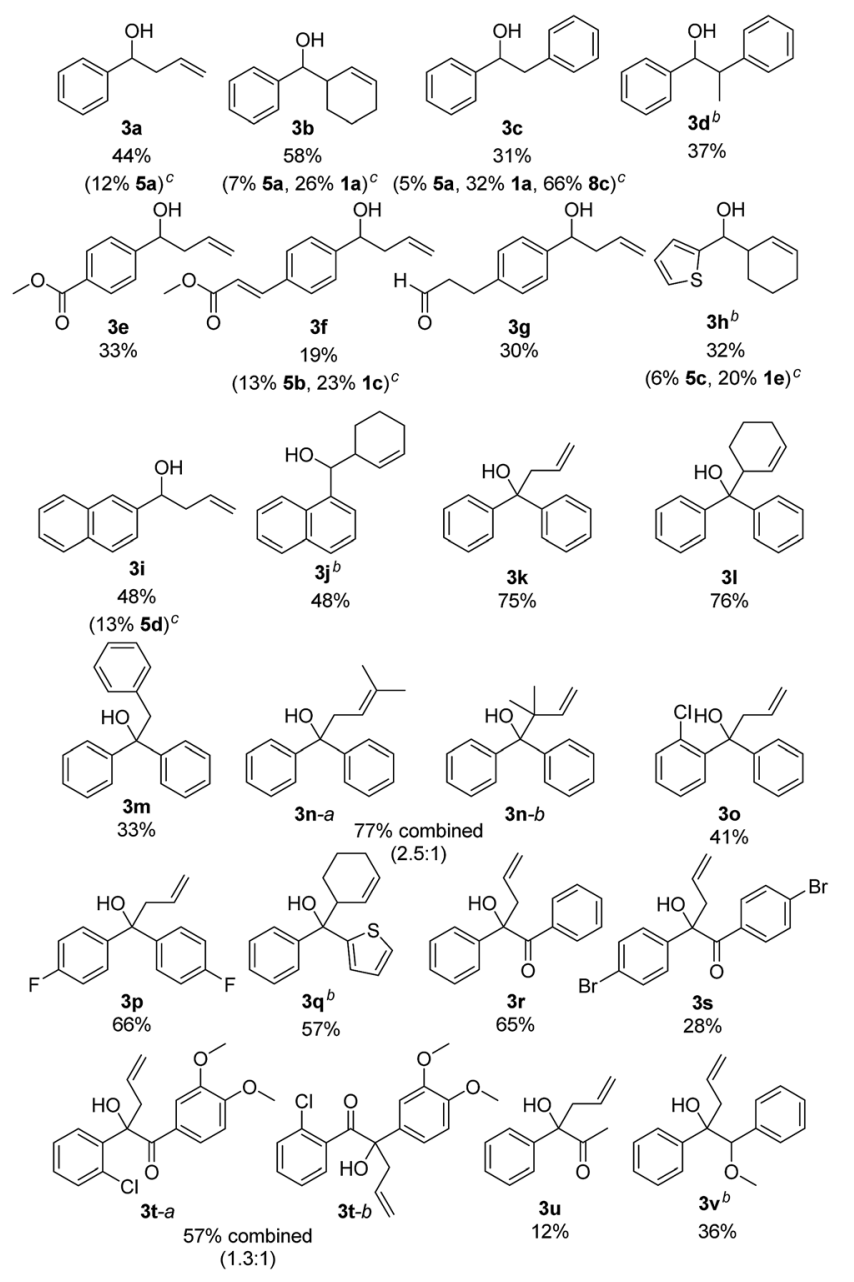

${ }^{a}$ The reactions were performed using 1 eq. (0.2 mmol) 1 and 2 eq. (0.4 mmol) 2 in $2 \mathrm{~mL}$ degassed DMA under nitrogen, all yields are of the isolated products. ${ }^{b}$ A $1: 1$ mixture of the syn- and anti-product was obtained. ${ }^{c}$ Yields of the side products were determined by crude NMR with 1,3,5-trimethoxybenzene as an internal standard. equivalents of the stoichiometric reagent $1 \mathrm{a}$ are required to form one equivalent of 5a.

The scope of the reaction was investigated using the optimized reaction conditions (Table 2). Apart from allyl bromide (2a) the reaction also worked in moderate to good yields with 3bromo cyclohexene (2b), benzyl bromide (2c) (1-bromoethyl) benzene (2d). When 3,3-dimethylallyl bromide (2e) was used, a mixture of product $3 \mathbf{n}-a$ and $3 \mathbf{n}-b$ was obtained, with $3 \mathbf{n}$ $a$ being the main product. Using alkyl or phenyl bromides did not lead to any product formation, probably because the radicals formed upon reduction and debromination are too unstable to undergo the coupling reaction. Aromatic aldehydes containing ester groups (3e, $\mathbf{3 f}$ ), or aliphatic aldehydes $(\mathbf{3 g})$ were also tolerated in the reaction with moderate yields. Notably, the reaction selectively takes place at the carbonyl group in benzylic position, while other carbonyl groups in the molecule remain unchanged. Apart from benzaldehydes which gave moderate yields (3a-3g) the reaction also works well with 1- and 2-naphthaldehyde $(\mathbf{3 i}, 3 \mathbf{j})$ and with the heterocyclic 2-thiophenecarboxaldehyde (3h). Good yields were obtained when benzophenone was used (3k-3n) and 1,2-diketones (3r-3u) are also viable substrates. Using a non-symmetric diketone with an electron rich and an electron poor arene gave a mixture of product 3t- $a$ and $3 \mathbf{t}-b$ with only a slight preference of the less electron rich position (3t- $a$ ). Product $3 \mathbf{u}$ shows an important advantage over the classical Barbier reaction, as the reaction selectively takes place at the sterically more hindered ketone next to the aromatic system. Halogen substituted substrates (3o, $\mathbf{3 p}, \mathbf{3 s}, \mathbf{3 t}$ ) and substrates containing a methoxy group (3v) were also tolerated. Alkyl aldehydes and ketones did not yield any product as they have significantly lower reduction potentials and can therefore not be reduced by $\mathbf{B}\left(E_{1 / 2}^{\mathrm{red}}(\right.$ benzophenone $1 \mathbf{e})$ $=-1.83 \mathrm{~V} v s$. $\mathrm{SCE},{ }^{20}$ compared to $E_{1 / 2}^{\mathrm{red}}($ cyclohexanone $2 \mathrm{~m})=$ $-2.79 \mathrm{~V} v s$. $\left.\mathrm{SCE}^{15 a}\right)$. Additionally, an aromatic system in $\alpha$ position to the carbonyl group seems to be required, probably due to the enhanced stability of the ketyl radical.

As moderate yields are obtained in many cases, the side products of the reaction were determined for selected examples (3a-3c, 3f, 3h, 3i). The diol homocoupling products 5 were observed in all examples. In some cases, remaining starting material was observed (3b, 3c, 3f, 3h) which indicates an incomplete reaction. While the homocoupling of 2 did not have any influence on the yield in most cases, it seems to have significant effect when benzyl bromide (2c) was used. This can be seen in the case of $3 \mathbf{c}$, where $66 \%$ of the homocoupling product 8 a was formed.

Control reactions have shown that under the reaction conditions the homocoupling products of benzaldehyde (5a) and allyl or benzyl bromide (8) could be observed (Scheme 2a). This confirms that the ketyl- $\left(\mathbf{1 a}^{\cdot-}\right)$ as well as the allyl- $\left(\mathbf{2 a}^{\mathbf{*}}\right)$ or benzyl radical $\left(2 \mathbf{c}^{\circ}\right)$ are present in the reaction mixture and lead to product formation via a radical-radical cross-coupling reaction. Notably, the homocoupling products of $\mathbf{2 a}$ and $\mathbf{2 c}$ are formed also without photocatalyst just by irradiating a mixture of the bromide 2 and DIPEA with $400 \mathrm{~nm}$ while the photocatalyst is required for the formation of the diol $\mathbf{5 a}$ from benzaldehyde. However, DIPEA and $400 \mathrm{~nm}$ light are both crucial for 
a) Homocoupling products formed under the reaction conditions

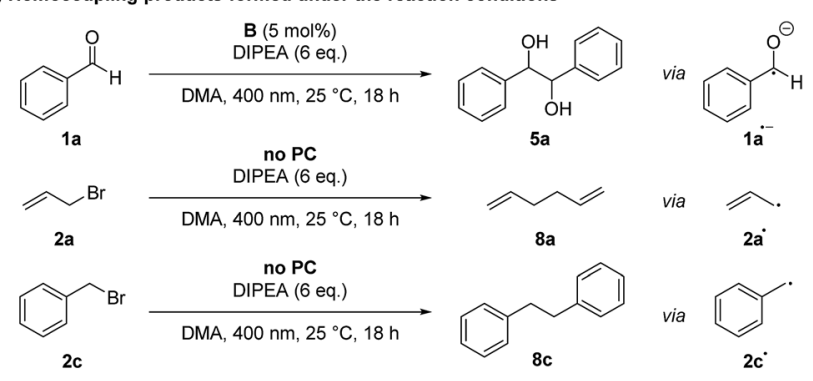

b) Trapping of allyl radicals
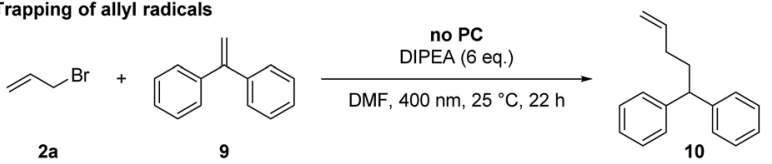

Scheme 2 Control reactions for radical-radical cross coupling.

the formation of allyl radicals, as irradiating only $2 \mathrm{a}$ at $400 \mathrm{~nm}$ as well as stirring a mixture of 2a and DIPEA in the dark or at $455 \mathrm{~nm}$ did not lead to the formation of homocoupling product 8a. It was also possible to trap the allyl radical, which was formed upon irradiation with 1,1-diphenylethylene (9) yielding product 10 (Scheme 2b).

Stern-Volmer fluorescence quenching experiments of photocatalyst $\mathbf{B}$ show that the excited state of $\mathbf{B}$ is quenched efficiently by benzaldehyde 1a, but not by allyl bromide (2a) or DIPEA (Fig. 1). These results are in accord with the prior observations, as they show that radical $\mathbf{1 a}^{\cdot-}$ is generated by a SET from $\mathbf{B}$ to 1a while the allyl radical $\left(2 \mathbf{a}^{*}\right)$ is formed without
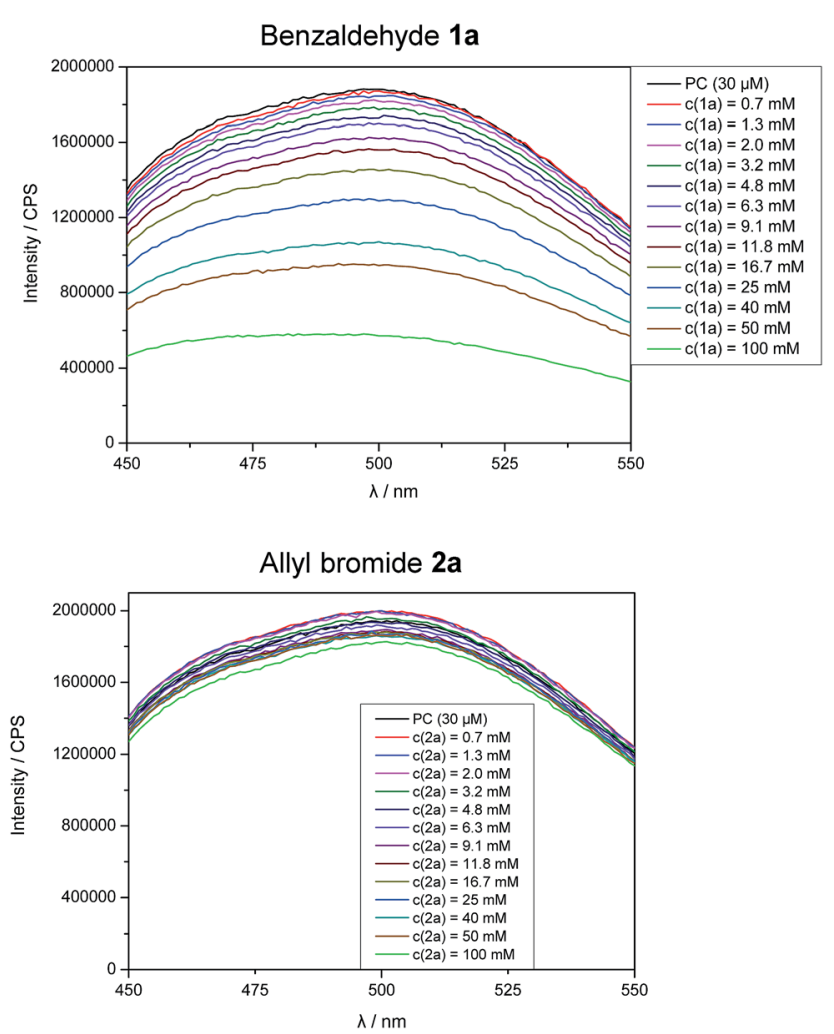

Fig. 1 Fluorescence quenching experiments of photocatalyst B upon addition of benzaldehyde (1a) and allyl bromide (2a). photocatalyst. According to cyclic voltammetry, benzaldehyde has a reduction potential of $-2.0 \mathrm{~V} v s$. SCE in DMF and should therefore not be in the range of photocatalyst $\mathbf{B}\left(E^{0 *}=-1.80 \mathrm{~V}\right.$ vs. SCE). ${ }^{19 b, 19 c}$ However, it is known that the potential of aldehydes and ketones can be lowered by activating the carbonyl group with Lewis acids ${ }^{15 d}$ or with the oxidized form of the tertiary amine $\left(\right.$ DIPEA $\left.^{\cdot+}\right) .{ }^{15 b}$ Indeed, CV-measurements show, that the signal for the reduction of 1a is clearly shifted to lower potentials upon addition of DIPEA and $\mathrm{LiBF}_{4}$ (Fig. 2). This effect could only be observed when both additives were present in the reaction mixture, which explains the role of $\mathrm{LiBF}_{4}$ in the reaction.

Although the mixture of allyl bromide and DIPEA has no detectable absorbance at $400 \mathrm{~nm}$, there seems to be a weak interaction between 2a and DIPEA leading to the absorption of small amounts of light and initiating an electron transfer from the amine to 2a. After a few minutes of irradiation, the absorption spectrum of the reaction mixture changes and an absorbance band with $\lambda_{\text {max,abs }}=413 \mathrm{~nm}$ arises, therefore enabling the efficient absorbance of $400 \mathrm{~nm}$ light and speeding up the reaction (Fig. 3).

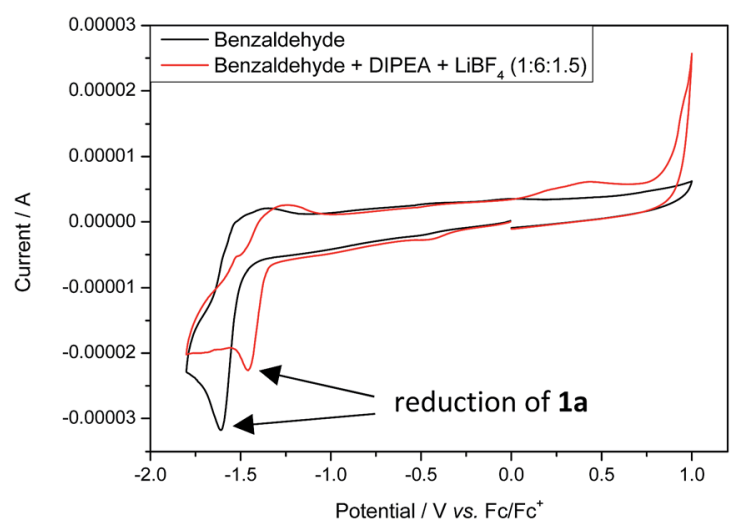

Fig. 2 Cyclic voltammograms of benzaldehyde (1a, black) and a mixture of $1 \mathrm{a}$ (1 eq.), DIPEA (6 eq.) and $\mathrm{LiBF}_{4}$ (1.5 eq.) (red); the peak that corresponds to the reduction of $1 \mathrm{a}$ is shifted to lower potentials upon addition of DIPEA and $\mathrm{LiBF}_{4}$.

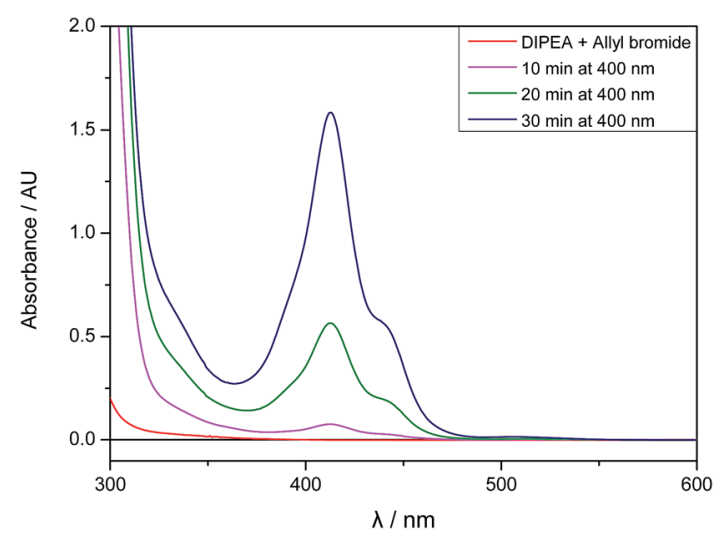

Fig. 3 UV/Vis absorption spectra of allyl bromide (2a, 1 eq.) and DIPEA (3 eq.) in DMA before irradiation and after 10, 20 and 30 minutes of $400 \mathrm{~nm}$ irradiation. 


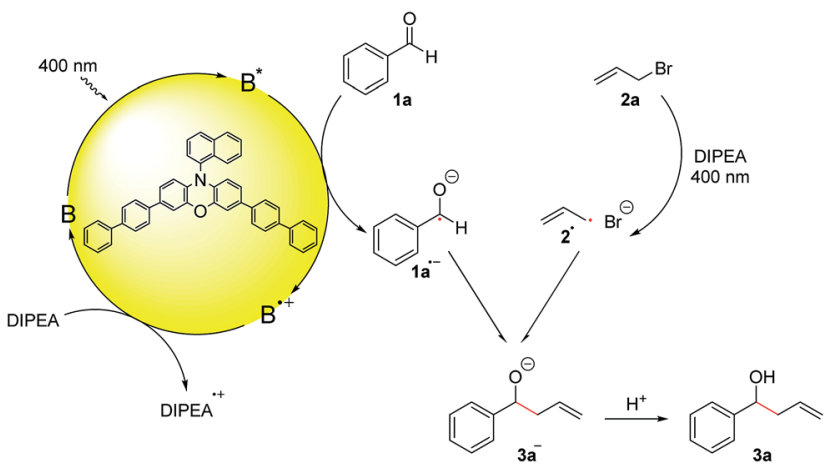

Scheme 3 Proposed reaction mechanism.

To gain further insight, the quantum yield of the reaction was measured. While the determined value of $\phi=7.6 \%$ is rather high for photocatalytic reactions, it is in accordance with the fast reaction times.

Based on these mechanistic investigations and recent literature reports, ${ }^{\mathbf{1 5 , 2 1}}$ we propose the reaction mechanism depicted in Scheme 3. Photocatalyst $\mathbf{B}$ is excited upon irradiation with $400 \mathrm{~nm}$ light and benzaldehyde (1a) can be reduced to the ketyl radical $\mathbf{1 a}^{-}$by a SET from the excited photocatalyst $\mathbf{B}^{*}$. DIPEA acts as a sacrificial electron donor to regenerate the photocatalyst from its oxidized form $\mathbf{B}^{\cdot+}$ to the ground state $\mathbf{B}$. Irradiation of allyl bromide and DIPEA initiates an electron transfer, which after the cleavage of $\mathrm{Br}^{-}$, leads to the formation of the allyl radical $2 \mathbf{a}^{\circ}$. The more persistent ketyl radical $1 \mathbf{a}^{0^{-21}}$ and the transient allyl radical $2 \mathbf{a}^{\cdot 22}$ recombine in a radicalradical cross-coupling, which is in accordance with the persistent radical effect, ${ }^{21,23}$ and after protonation, the desired product $3 \mathbf{a}$ is formed.

\section{Conclusion}

In summary, we have developed a photocatalytic version of the Barbier-type reaction, which generates allylic or benzylic alcohols from aldehydes or ketones and allyl- or benzyl bromides under mild conditions via a radical-radical cross-coupling. Instead of using stoichiometric amounts of zerovalent metal as a reductant to generate an organometallic carbanion synthon, we use an organic photocatalyst, a tertiary amine and visible light to reduce both substrates to the corresponding radicals. The cross-coupling of these radicals leads to the desired product and enables a photocatalytic two electron process.

\section{Conflicts of interest}

There are no conflicts to declare.

\section{Acknowledgements}

This work was supported by the German Science Foundation (DFG, GRK 1626). This project has received funding from the European Research Council (ERC) under the European Union's
Horizon 2020 research and innovation programme (grant agreement No. 741623). We thank Dr Rudolf Vasold for GS-MS measurements and Regina Hoheisel for cyclic voltammetry measurements.

\section{Notes and references}

1 P. Barbier, C. R. Acad. Sci., 1899, 128, 110-111.

2 (a) T. A. Killinger, N. A. Boughton, T. A. Runge and J. Wolinsky, J. Organomet. Chem., 1977, 124, 131-134; (b) C. Petrier and J. L. Luche, J. Org. Chem., 1985, 50, 910-912; (c) F. Zhou and C. J. Li, Nat. Commun., 2014, 5, 4254; (d) L. Keinicke, P. Fristrup, P. O. Norrby and R. Madsen, J. Am. Chem. Soc., 2005, 127, 15756-15761.

3 (a) C.-J. Li and W.-C. Zhang, J. Am. Chem. Soc., 1998, 120, 9102-9103; (b) S. Li, J.-X. Wang, X. Wen and X. Ma, Tetrahedron, 2011, 67, 849-855.

4 Y. Yamamoto and N. Asao, Chem. Rev., 1993, 93, 2207-2293.

5 (a) A. Rizzo and D. Trauner, Org. Lett., 2018, 20, 1841-1844;

(b) B. M. Trost and A. B. Pinkerton, Tetrahedron Lett., 2000, 41, 9627-9631.

6 J. Nokami, J. Otera, T. Sudo and R. Okawara, Organometallics, 1983, 2, 191-193.

7 (a) K. Frimpong, J. Wzorek, C. Lawlor, K. Spencer and T. Mitzel, J. Org. Chem., 2009, 74, 5861-5870; (b) T.-H. Chan and M.-C. Lee, J. Org. Chem., 1995, 60, 4228-4232. 8 S. Wu, Y. Li and S. Zhang, J. Org. Chem., 2016, 81, 8070-8076. 9 C.-J. Li, Y. Meng, X.-H. Yi, J. Ma and T.-H. Chan, J. Org. Chem., 1997, 62, 8632-8633.

10 (a) K. Zeitler, Angew. Chem., Int. Ed., 2009, 48, 9785-9789; (b) J. Xuan and W. J. Xiao, Angew. Chem., Int. Ed., 2012, 51, 68286838; (c) N. A. Romero and D. A. Nicewicz, Chem. Rev., 2016, 116, 10075-10166; (d) D. Ravelli, S. Protti and M. Fagnoni, Chem. Rev., 2016, 116, 9850-9913; (e) J. P. Goddard, C. Ollivier and L. Fensterbank, Acc. Chem. Res., 2016, 49, 1924-1936.

11 (a) K. Hironaka, S. Fukuzumi and T. Tanaka, J. Chem. Soc., Perkin Trans. 2, 1984, 1705; (b) Y. Zhang, R. Qian, X. Zheng, Y. Zeng, J. Sun, Y. Chen, A. Ding and H. Guo, Chem. Commun., 2015, 51, 54-57.

12 M. Chen, X. Zhao, C. Yang and W. Xia, Org. Lett., 2017, 19, 3807-3810.

13 (a) O. Ishitani, C. Pac and H. Sakurai, J. Org. Chem., 1983, 48, 2941-2942; (b) O. Ishitani, S. Yanagida, S. Takamuku and C. Pac, J. Org. Chem., 1987, 52, 2790-2796; (c) T. Ghosh, T. Slanina and B. König, Chem. Sci., 2015, 6, 2027-2034.

14 T. Shibata, A. Kabumoto, T. Shiragami, O. Ishitani, C. Pac and S. Yanagida, J. Phys. Chem., 1990, 94, 2068-2076.

15 (a) F. R. Petronijevic, M. Nappi and D. W. MacMillan, J. Am. Chem. Soc., 2013, 135, 18323-18326; (b) M. Nakajima, E. Fava, S. Loescher, Z. Jiang and M. Rueping, Angew. Chem., Int. Ed., 2015, 54, 8828-8832; (c) E. Fava, A. Millet, M. Nakajima, S. Loescher and M. Rueping, Angew. Chem., Int. Ed., 2016, 55, 6776-6779; (d) W. Ding, L. Q. Lu, J. Liu, D. Liu, H. T. Song and W. J. Xiao, J. Org. Chem., 2016, 81, 7237-7243; (e) C. Wang, J. Qin, X. Shen, R. Riedel, 
K. Harms and E. Meggers, Angew. Chem., Int. Ed., 2016, 55, 685-688.

16 (a) G. Pandey, S. Hajra, M. K. Ghorai and K. R. Kumar, J. Org. Chem., 1997, 62, 5966-5973; (b) J. Du and T. P. Yoon, J. Am. Chem. Soc., 2009, 131, 14604-14605; (c) M. A. Ischay, M. E. Anzovino, J. Du and T. P. Yoon, J. Am. Chem. Soc., 2008, 130, 12886-12887; (d) K. T. Tarantino, P. Liu and R. R. Knowles, J. Am. Chem. Soc., 2013, 135, 10022-10025; (e) L. J. Rono, H. G. Yayla, D. Y. Wang, M. F. Armstrong and R. R. Knowles, J. Am. Chem. Soc., 2013, 135, 1773517738; $(f)$ E. Fava, M. Nakajima, A. L. Nguyen and M. Rueping, J. Org. Chem., 2016, 81, 6959-6964; $(g)$ W. Li, Y. Duan, M. Zhang, J. Cheng and C. Zhu, Chem. Commun., 2016, 52, 7596-7599.

17 (a) L. Qi and Y. Chen, Angew. Chem., Int. Ed., 2016, 55, 1331213315; (b) K. N. Lee, Z. Lei and M. Y. Ngai, J. Am. Chem. Soc., 2017, 139, 5003-5006.

18 Y. Nishigaichi, T. Orimi and A. Takuwa, J. Organomet. Chem., 2009, 694, 3837-3839.
19 (a) J. C. Theriot, C. H. Lim, H. Yang, M. D. Ryan, C. B. Musgrave and G. M. Miyake, Science, 2016, 352, 10821086; (b) R. M. Pearson, C. H. Lim, B. G. McCarthy, C. B. Musgrave and G. M. Miyake, J. Am. Chem. Soc., 2016, 138, 11399-11407; (c) Y. Du, R. M. Pearson, C. H. Lim, S. M. Sartor, M. D. Ryan, H. Yang, N. H. Damrauer and G. M. Miyake, Chem.-Eur. J., 2017, 23, 10962-10968; (d) B. G. McCarthy, R. M. Pearson, C. H. Lim, S. M. Sartor, N. H. Damrauer and G. M. Miyake, J. Am. Chem. Soc., 2018, 140, 5088-5101.

20 P. J. Wagner, R. J. Truman, A. E. Puchalski and R. Wake, J. Am. Chem. Soc., 1986, 108, 7727-7738.

21 J. L. Jeffrey, F. R. Petronijevic and D. W. MacMillan, J. Am. Chem. Soc., 2015, 137, 8404-8407.

22 D. Griller and K. U. Ingold, Acc. Chem. Res., 1976, 9, 13-19. 23 (a) A. Studer, Chem.-Eur. J., 2001, 7, 1159-1164; (b) J. D. Cuthbertson and D. W. MacMillan, Nature, 2015, 519, 74-77. 